\title{
PSORÍASE. PSORÍACO, PSÓRICO, PSORIÁTICO, PSORIÁSICO
}

Joffre Marcondes de Rezende ${ }^{l}$

À Dra. Ana Gláucea Quarto Silva

A psoríase é conhecida desde a Antiguidade. É uma doença inflamatória, crônica da pele, não contagiosa, multifatorial, com um componente genético e sujeita a períodos de agravamento na dependência de outros fatores. Caracteriza-se por manchas avermelhadas com a formação de escamas e placas nacaradas que se soltam. Acomete principalmente as superfícies extensoras das extremidades e do tronco. Uma de suas complicações mais frequentes é a chamada artrite psoriásica.

Psoríase vem do grego $\psi \omega \omega ́ \boldsymbol{\rho \alpha}$ (psora), que significa sarna, prurido e, por extensão, outras lesões cutâneas.

Segundo alguns autores, Hipócrates descreveu lesões cutâneas

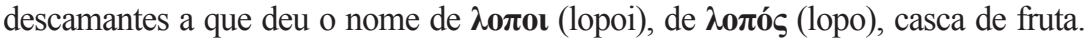
Não conseguimos localizar a fonte original desta informação tanto no Corpus hippocraticum como em artigos publicados sobre psoríase, os quais utilizaram fonte secundária.

Hipócrates usou ainda o termo $\psi \omega \rho \iota \boldsymbol{\alpha}$ (psoria) em duas passagens, ambas se referindo ao sistema urinário. A primeira está no livro Natureza do homem: (1) "A urina, antes clara, que de tempos em tempos se torna espessa contendo matéria com aspecto de farelo, indica psoríase da bexiga". A outra passagem se encontra no Aforismo IV, 77 (2): "Quando a urina é espessa e com ela sai matéria semelhante a farelo, significa psoríase da bexiga". É de supor-se que o termo psoria foi aqui empregado no sentido de descamação, como na psoríase cutânea.

Celsus descreveu, sob o nome de vitiligo, três variedades de psoríase: alphos, semelhante à lepra; melas, quando apresentava alguma coloração e leuce, de um branco brilhante e resistente ao tratamento (3).

1 Professor Emérito da Universidade Federal de Goiás.

Endereço para correspondência: $\quad$ E-mail: joffremr@ig.com.br

Recebido para publicação em: 23/02/2014 
Há divergência entre os historiadores sobre quem teria usado pela primeira vez a palavra psoríase. Segundo Marcovecchio, teria sido Dioscórides, que a empregou como sinônimo de $\psi \omega \rho \alpha$, do verbo $\psi \boldsymbol{\alpha} \omega$, coçar, arranhar (4).

A maioria dos autores, no entanto, credita a Galeno a criação do termo $\psi \omega$ pıoбı com o acréscimo do sufixo -iasis para nomear a enfermidade (5). Todavia, Galeno teria confundido a psoríase com a dermatite seborreica (6).

Vários autores descreveram lesões cutâneas com aspecto de psoríase usando outras denominações ou confundindo-a com outras dermatoses. Desde os tempos bíblicos até o século XVIII, a psoríase era considerada doença contagiosa e confundida com a lepra. Somente na década de 1840, von Hebra separou definitivamente as duas entidades (7).

A partir de então, a psoríase firmou-se como uma doença individualizada, diferenciando-se das demais dermatoses por sua etiopatogenia, histopatologia, sintomas, formas clínicas, evolução e tratamento.

Há um consenso quanto ao nome psoríase para a doença, por vezes abreviado para psora. $\mathrm{O}$ mesmo não se dá em relação aos adjetivos correlatos. Nada menos que quatro modalidades de adjetivos têm sido usadas: psoríaco, psórico, psoriático e psoriásico. As duas últimas variedades não se encontram dicionarizadas em português, apesar de serem largamente usadas na terminologia médica. As formas averbadas em todos os léxicos consultados são psoríaco $e$ psórico. Os dicionários Houaiss (2009), Aurélio (1999) e Francisco Borba (2002) registram somente psoríaco; Domingos Vieira (1871-1874), Nascentes (1961-1967) e Michaelis (1998), somente psórico; Caldas Aulete (1980), Silveira Bueno (1963), Laudelino Freire - 3. ed. (1957), Morais Silva (1949-1959), José Pedro Machado (1977) e o Vocabulário da Academia Brasileira de Letras, ambas as formas (8-18).

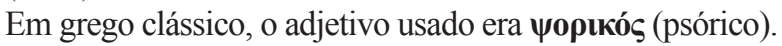

Psoriático e psoriásico, apesar de sua ausência nos léxicos, são considerados sinônimos e empregados indistintamente na literatura médicocientífica. A forma psoriático é própria da língua inglesa (psoriatic) e psoriásico, do espanhol e português. Na base de dados da literatura latino-americana e do Caribe, indexada em três idiomas (português, espanhol e inglês) pela BIREME (Lilacs), há, até esta data (24.01.2014), 118 entradas com a forma artrite psoriásica e $96 \mathrm{com}$ artigos em que se usou artrite psoriática. Em nenhum caso foi empregado psoríaco ou psórico (19). A Sociedade Brasileira de Reumatologia adota psoriásica para designar a artrite que ocorre na psoríase - artrite psoriásica.

Vemos, assim, que os autores de trabalhos médicos rejeitam as formas psoríaco e psórico, averbadas nos dicionários, preferindo as denominações já consagradas pelo uso. Conforme recomenda Becker: "Na convenção sobre termos biomédicos deve atentar-se, em primeiro lugar, ao uso da maioria e à tradição" (20).

É bom lembrar que os lexicógrafos não fazem a língua, apenas registram as palavras em uso em determinado momento da sua história. E, tratando-se de termos médicos, compete aos médicos estabelecer a sua própria terminologia. Aqui 
não se trata de neologismos e, sim, de uma opção entre palavras com o mesmo radical e significado, que diferem entre si apenas quanto ao sufixo empregado. Cabe aos dicionários adaptarem-se aos termos médicos em uso e não o inverso.

\section{REFERÊNCIAS}

1. Hippocrates. Sobre a natureza do homem. Trad. de Jones WHS. Cambridge, Harvard University Press, 1967. p. 38.

2. Idem. Aforismos.Idem, idem, p. 155-156.

3. Celsus. De Medicina. Cambridge. Harvard University Press, vol. 2, 1961. p. 173.

4. Marcovecchio E. Dizionario etimologico storico dei termini medici. Firenze, Ed. Festina Lente, 1993.

5. Durling RJ. A dictionary of medical terms in Galen. Leiden, ed. E. J. Brill, 1993.

6. Romiti R, Maragno L, Arnone M, Fonseca MD, Takahashi. Psoríase na infância e na adolescência An Bras Dermatol 84: 9-20, 2009.

7. Hebra F. Diseases of skin including the exanthemata. vol. 1, trad. de C. Hilton Fagge. London, The New Sydenham Society, 1866. p. 63.

8. Houaiss A. Dicionário eletrônico Houaiss, 2009.

9. Ferreira AB de H. Novo dicionário Aurélio da língua portuguesa. 3.ed. Curitiba, Ed. Positivo, 2004.

10. Borba FS. Dicionário de usos do português do Brasil. São Paulo, Editora Ática, 2002.

11. Michaelis. Moderno dicionário da língua portuguesa. São Paulo, Cia. Melhoramentos, 1998.

12. Nascentes A. Dicionário da língua portuguesa. (4 vol.) Rio de Janeiro. Academia Brasileira de Letras, 1961-1967.

13. Vieira Frei Domingos. Grande dicionário português ou Tesouro da língua Portuguesa. Porto, Ernesto Chardron e Bartholomeu H. de Moraes, 1871-1874.

14. Aulete FJC, Garcia H de. Dicionário contemporâneo da língua portuguesa. 3.ed. Rio de Janeiro, Ed. Delta, 1980.

15. Bueno F da S. Grande dicionário etimológico-prosódico da língua portuguesa. São Paulo, Ed. Saraiva, 1963.

16. Morais Silva A de. Grande dicionário da língua portuguesa. 10.ed. (12 vol.), Lisboa, Confluência, 1949-1959.

17. Machado JP. Dicionário etimológico da língua portuguesa. 3.ed. Lisboa, Livros Horizonte, 1977.

18. Academia Brasileira de Letras. Vocabulário ortográfico da língua portuguesa. 5a. ed., São Paulo, Ed. Global, 2009.

19. Bireme. (Lilacs). Disponível em http://bases.bireme.br/cgi-bin/wxislind.exe/iah/online/Acessado em 24.01.2014.

20. Becker I. Nomenclatura biomédica no idioma português do Brasil. São Paulo, Liv. Nobel, 1968. p. 337. 
